\title{
Effects of Propolis Supplementation on The Severity of Disease In Irritable Bowel Syndrome Subjects: A Randomized, Double-Blind Clinical Trial
}

Mahsa Miryan

Tabriz University of Medical Sciences

Pejman Alavinejad

Ahvaz Jundishapur University of Medical Sciences

Mohammadreza Abbaspour

Mashhad University of Medical Sciences

Davood Soleimani

Kermanshah University of Medical Sciences

Alireza Ostadrahimi ( $D$ Ostadrahimi@tbzmed.ac.ir)

Tabriz University of Medical Sciences

\section{Research Article}

Keywords: Propolis, Irritable bowel syndrome, IBS-QOL, IBS-SSS, Dietary intake, Anxiety state

Posted Date: February 8th, 2021

DOI: https://doi.org/10.21203/rs.3.rs-144646/v1

License: () (1) This work is licensed under a Creative Commons Attribution 4.0 International License. Read Full License 


\section{Abstract}

The effects of propolis, a well-known functional food, on irritable bowel syndrome (IBS), a chronic gastrointestinal disorder, in humans have yet to be investigated. This study evaluated propolis effects in IBS subjects. In this clinical study, 56 patients with IBS diagnosed by Rome IV criteria were assigned for 6 weeks randomly to the study groups. At the baseline and endpoint phase, patients' gastrointestinal symptoms, quality of life (QOL), anxiety state, dietary intakes, and anthropometric indices were assessed. Independent t-test, paired t-test, Mann-Whitney U test, Wilcoxon, Fisher's exact test, repeated measures analysis of variance and logistic regression test were used for analyzing the data. To adjust the effect of confounders, covariance analysis was used. The results of this study showed that after modulating the effect of potential confounders, propolis supplementation increased the chance of improving IBS severity by 6.22 (with a confidence interval of: $1.33-1.14$ and $P=0.035$ ). A significant abdominal pain improvement, anxiety state, and bowel habits dissatisfaction reduction was observed within- and between-group differences in propolis group compared to the placebo group $(P=0.040, P=0.035, P=0.029$, retrospectively). The overall score of quality of life and its domains in the propolis group was statistically significant, but in comparison between the two groups, this difference was not significant. Also, regards to the food intakes and anthropometric indices, there were no significant differences between and within the two study groups. This study illustrated that propolis supplementation could be used as adjunctive therapy in IBS disease to reduce abdominal pain and anxiety state.

\section{Introduction}

Irritable bowel syndrome (IBS) is a common functional gastrointestinal (GI) disease that is manifested by recurrent abdominal pain and altered bowel addiction (1). No specific markers or laboratory parameters are available yet to diagnose the disease. Recently in clinical practice, the Rome IV criteria have been proposed as the latest diagnostic tool for IBS, based on the GI symptoms (2). IBS is estimated to affect women approximately three times more than men, with an overall prevalence of $10 \%(3,4)$.

The pathophysiology of IBS is not well known, but several factors have been attributed to an individual's susceptibility to IBS including the alterations in gut microbiota, brain-gut interaction, motility or/and permeability, and intestinal immune system function; GI microscopic inflammation; psychological stress; chronic infections; specific nutrients and foods; and genetic factors (5). Recent investigations also reveal the role of inflammatory and oxidative stress factors in increasing nervous system sensitivity and perception of abdominal pain in IBS subjects (3).

Various strategies are recommended to improve or even treat IBS symptoms but, unfortunately, often with little success so far (6). The initial strategy would be to base the prohibition of consuming gas-producing foods by following a diet low in FODMAPs. But if this is not helpful, the consumption of these special foods should not be avoided for a long time (7). Emerging evidence has shown an important role of the modulating GI immune system and gut microbiota using prebiotic and/or probiotic supplements in ameliorating the symptoms of IBS, which has been beneficial for many patients (8). Dietary polyphenols and their secondary metabolites also have a crucial role in maintaining the balance of the GI microbiome by altering bacterial metabolites that can raise mucin gene expression that resulted in an increase in the thickness of the GI mucosal layer and also reduction in GI inflammation (9).

Propolis, a popular traditional medicine, is a resinous hive product collected by honeybees from varied petals and plant buds sources (10). With the advent of new methods such as high-performance liquid chromatography (HPLC), more than 300 types of phytochemicals have been identified in this hive product, mainly from the family of polyphenols. They are secondary plant metabolites with well-known antioxidant properties (11). Recent studies have been shown that propolis, due to the unique diversity of its components (especially polyphenols), not only has antioxidant effects but also can modulate the inflammatory pathways, immune system function, gut microbiota, and GI permeability (12-15).

Considering the wide range of probable causes and symptoms in IBS patients which propolis may modify; we aimed to evaluate the efficacy of propolis supplementation on the severity of gastrointestinal symptoms, dietary intakes, anxiety state, and quality of life in patients with IBS.

\section{Materials And Methods}

\section{Study design and subjects}

Page 2/18 
This randomized, double-blind, parallel-design, placebo-controlled clinical trial was conducted on subjects who their IBS has been determined by a gastroenterologist according to Rome IV criteria. Patients were recruited from the Soroush Special Clinic of Ahvaz, Iran, between September 2019 and January 2020. Based on the Rome IV criteria, patients who had recurrent abdominal pain or discomfort (at least 1 day/week in the last 3 months) were identified as an IBS patient if he/she had at least two of the following criteria:

I. Improvement with defecation

II. Onset related to a change in stool frequency

III. Onset related to exchange in stool form (appearance)

\section{Enrolled participants}

The inclusion criteria in this trial included patients aged 18-65 years who had a constipation subtype of IBS (IBS-C) or a mixed subtype of IBS (IBS-M) based on the Bristol stool form scale (BSFS); have no allergy to bee products; and fill out a written consent form. The exclusion criteria of the study were pregnancy or breastfeeding; patients with malignancy or other chronic GI diseases; regular use of drugs that modify GI movements (such as Metoclopramide, Cisapride, Narcotics, Diphenoxylate, and etc.); regular use of laxatives and/or antibiotics; the history of major surgery in the digestive system (such as Billroth's operation, having an ostomy and any resection of any part of the digestive tract); being on diet; regular use of prebiotic and/or probiotic compounds; and use of psychotherapy drugs.

\section{Excluded participants}

Patients with taking less than $80 \%$ of their supplements, unwilling to continue collaboration in the study, experiencing severe physical and mental trauma, or changing their diet plan or physical activity during the study were withdrawn from follow-up.

The trial protocol, available at Iranian Registry of Clinical Trials (https://en.irct.ir/trial/40983, registration date: 26/12/2019, Registration number: IRCT20190708044154N1), was approved by the Ethics Committee of Tabriz University of Medical Sciences. This trial was performed in accordance with the Declaration of Helsinki. All patients were provided verbally with information on the objectives, benefits, and possible health risks of the trial at the time of enrollment and then provided written informed consent.

\section{Randomization and intervention}

Eligible patients were randomly allocated in a 1:1 ratio to receive propolis or placebo tablets. In this study, a random-number table was used to generate randomization sequences with a block size of 4 and stratification according to IBS subtypes and sex. For proper blinding, the propolis and placebo were prepared in precisely the same color, size, odor, and packaging. Also, numbered drug containers were used to conceal random allocation. No one was aware of treatment assignments, except the pharmacist.

\section{Supplementation}

The supplements were prepared by Mashhad School of Pharmacy, Mashhad University of Medical Sciences, Iran; under the supervision of a clinical pharmacist. Propolis tablets consist of $450 \mathrm{mg}$ of propolis extract (containing $90 \mathrm{mg}$ of the polyphenols and $67 \mathrm{mg}$ flavonoids), whereas the placebo tablets contain microcrystalline cellulose (a powder that had no taste, calories, smell, or nutrients) and various edible colors (16). The tablets were similar in color, shape, and packaging; and were administrated before lunch and dinner for six weeks. The optimal dosage of propolis $(900 \mathrm{mg} /$ day) was extracted from animal studies which its method is completely described in the published protocol article of this study (17). Due to the same mechanism of propolis and pre-and probiotics for intestinal microflora, a period of six weeks is adequate to boost intestinal microflora and/or Gl symptoms in patients based on former studies $(18,19)$. One of the researchers was responsible for follow-up patients by phone calls, weekly. She was asked each patient to report any adverse effect they may be experienced during the study, and fill out the supplement checklist on which patients recorded supplements consumed. In each visit, compliance was assessed by the supplement checklists and by counting the return of uneaten supplements.

\section{Primary Outcome}


The main outcome of the trial was the percentage of patients with an improvement of at least one stage of IBS disease from baseline to the sixth week of intervention. To assess IBS severity, the IBS symptom severity scale (IBS-SSS) was used. It was filled out by patients pre- and post-intervention. The IBSSS questionnaire included five clinically applicable items over a 10-day period include: I) the abdominal pain intensity, II) the frequency of abdominal pain, III) the abdominal distension intensity, IV) dissatisfaction with bowel movements, and V) potential impact of IBS on the patient's daily life. The mean score of each scale is a maximum of 100 and the questionnaire total score reaches a maximum of 500 , eventually. Scores of $<75,75-175,175-300$, and $\geq 300$ displayed mild, moderate, and severe stages of the IBS disease, respectively (20).

\section{Secondary outcomes}

The secondary outcomes of the trial were change in IBS-quality of life (IBS-QoL), anxiety state, body mass index (BMI), and waist circumference (WC) to the sixth week of intervention. Patients' quality of life (QoL) was assessed using the 34-item IBS-QoL questionnaire which consists of 8 subscales including (a) food avoidance, (b) dysphoria, (c) body image, (d) interference with activity, (e) health worry, (f) sexual, social reaction, and (g) relationships.(21) Participant responses to all the 34 items were summed and then transformed to a 0-to-100 scale. The Beck anxiety inventory (BAI) was used to assess patients' anxiety status. BAl is a 21item scale validated as an anxiety screening questionnaire based on Fydrich et al (22). Each item expresses one of the symptoms of anxiety commonly experienced by patients who are clinically anxious or in anxious conditions. The questionnaire scores ranged from 0 to 63. The anxiety state was classified as minimal (scores range from 0 to 7 ), mild (scores range from 8 to 15), moderate (scores range from 16 to 25), and severe (scores range from 30 to 63) (23). Due to the anxiety is a potential confounder for the study it was assessed before and after the intervention and its effect was adjusted at the end of the trial by the statistical analysis. Weight was measured close to $0.1 \mathrm{~kg}$ by a calibrated scale (Seca, Hamburg, Germany) with light clothes and no shoes. Height was measured close to $0.1 \mathrm{~cm}$ by an audiometer (Seca, Hamburg, Germany). Then, BMI was calculated as weight $(\mathrm{kg}) / \mathrm{height}^{2}(\mathrm{~m})$. WC was measured as the smallest circumference between the costal and iliac crests using a non-stretchable measuring tape to the nearest $0.1 \mathrm{~cm}$.

\section{Confounding factors assessment:}

Dietary intake was appraised by a three-day food record (two nonconsecutive weekdays, and one weekend) before and after the intervention. Dietary intakes were assessed by the Nutritionist IV software. A validated international physical activity questionnaireshort form (IPAQ-SF) was used for evaluating the physical activity of the patients at baseline and the endpoint. Responses were converted to Metabolic Equivalent Task minutes per week (MET-min/ week). It consisted of 7 questions that will collect all types of physical activity as part of daily life (24).

\section{Statistical analysis}

Statistical analysis was conducted using IBM SPSS Statistics software, version 16 (SPSS Inc., and Chicago, IL, USA). The sample size was 28 patients in each group by assuming a between-group difference of $25 \%$ points in the main outcome (19) on the basis of a two-sided significance level of $5 \%$, a power of $80 \%$, and a withdrawal rate of $30 \%$ with the use of $A^{\prime} H e r n ' s$ single-stage phase II methodology (25).

According to the patterns of missing data, a suitable multiple imputation approach followed for completing missing data. The authors checked the data entry double times.

Data were presented as mean (SD) for numerical data, frequency (percentage) for categorical variables, and median (25th, 75th) for values with skewed distribution. For evaluating the differences between the 2 groups at baseline, independent samples t-test or Mann-Whitney $\mathrm{U}$ test were used for values with normal and non-normal distribution, respectively. Paired samples t-test and Wilcoxon signed-rank test were used for assessing within-group changes, as appropriate. To judge between-and within-group differences of qualitative variables, Fisher's exact test and Sign test were applied, respectively. For adjusting the confounding factors the analysis of covariance (ANCOVA) test was used. In this study two separate models were used to achieve the goal. Model 1 included baseline values, and model 2 included the model 1, and changes in physical activity, and energy intake. P values under 0.05 were observed as statistically significant. The binary logistic regression was used to calculate the odds of achieving the main outcome with propolis supplementation in both crude and adjusted models. Further details of the study method are presented in the protocol article of this study (17). 


\section{Results}

\subsection{General characteristics of the trial}

Between September 2019 and January 2020, a total of 168 patients were enrolled in the trial and were screened, of whom 56 patients met eligibility criteria and underwent randomization (28 patients to the propolis group and 28 patients to the placebo group). A total of 51 patients ( 26 patients in the propolis group and 25 patients in the placebo group) completed this trial while 5 patients ( 3 patients in the placebo group and 2 patients in the propolis group) discontinued the study for a reason unrelated to the trial treatment and 1 patient in the propolis group discontinued the study because of a drug-related adverse event (abdominal distention). The trial flowchart is shown in Figure 1. There was no significant differences in terms of compliance rates between the propolis and placebo groups at the end of the trial (93\% for propolis vs. $90 \%$ for placebo; P: 0.73 ).

\subsection{Demographic characteristics}

The baseline demographic characteristics of the participants in both groups are shown in Table 1. Prior to the intervention, there were no statistically significant differences between the two groups in terms of gender, marital status, education levels, occupational status, physical activity levels (metabolic equivalents), IBS subtypes, duration of IBS symptoms, and anxiety state.

\section{Dietary intakes,anthropometric indices, and physical activity}

As observed in Table 2, caffeine and lactose intake had a significant change throughout the study in both groups, whereas other nutrients did not significantly change. However, these changes were related to the effect of time and were not the effect of the intervention. The intakes of energy, macronutrients, lactose, and caffeine had no significant changes from baseline to the end of the trial in both groups $(P>0.05)$. None of the participants in the present study reported alcohol consumption at the beginning and during the study. Also, there were no significant changes in terms of weight, BMI, WC, and physical activity (METs) in the both group as observed in Table 3.

\subsection{Severity of IBS}

As shown in Table 5, overall scores of IBS symptoms severity and all its components scores significantly reduced in the propolis group at the end of the trial $(P<0.05)$. In the placebo group, the scores of severity of abdominal distention decreased significantly while other components did not change at the end of the trial $(P<0.05)$. There were significant between-group differences in the severity of abdominal pain and dissatisfaction with bowel habits after adjusting the potential confounders based on model 2 .

The changes in the grade of IBS are illustrated in Figure 2. At the end of the trial, the grade of IBS decreased in 21 patients (80.7\%) and had no change in $5(19.3 \%)$ who received propolis supplements. The improvement in the grade of IBS was statistically significant in the propolis group ( $\mathrm{P}=0.001)$. In the placebo group, the grade of IBS decreased in $13(52 \%)$ patients; had no changes in $11(44 \%)$ patients, and increased in $1(4 \%)$ patient. The improvement in the grade of IBS was not significant in the placebo group $(P=0.501)$. Mann-Whitney $U$ test showed that the proportion of patients experienced reduction in the IBS severity by at least one grade was significantly higher in the propolis group than the placebo group $(80.7 \% \mathrm{vs.} 52 \% \mathrm{P}=0.015)$. In addition, the adjusted odds of improvement of IBS was $6.22(95 \% \mathrm{Cl}: 1.14$ to $33.9 ; \mathrm{P}=0.035)$ with propolis treatment as compared with placebo.

\subsection{Quality of life}

As shown in Table 4, there were no significant between-group changes for the total QOL-IBS and its components scores after adjusting the potential confounders based on model 1 throughout the study, except for body image. In model 2 after adjusting the potential confounders no significant between-group changes were observed. The significant within-group reduction in the QOL-IBS and its components scores were observed in the propolis group, compared to the placebo group post-intervention $(P<0.05)$.

\subsection{Anxiety}

Propolis supplementation decreased the frequency of severe anxiety in IBS patients from $23.07 \%$ to $7.69 \%$. Additionally, it raised the frequency of minimum anxiety from $23.07 \%$ to $34.61 \%$, and mild anxiety from $30.76 \%$ to $46.15 \%$ in the propolis group. Also, another finding of this study was that there was a significant reduction in patients' anxiety in the propolis group versus the placebo group 
throughout the study ( 16.88 to 11.19 versus 17.68 to $16.44 ; \mathrm{P}=0.040$ ). It was also found that the anxiety score of patients' withingroup significantly decreased in the propolis group contrary to the placebo group ( $P=0.002, P=0.462$, retrospectively).

\section{Discussion}

The current trial revealed that supplementation with $900 \mathrm{mg} /$ day of propolis for 6 weeks significantly improved anxiety state, some clinical symptoms of IBS in patients with IBS (abdominal pain, dissatisfaction with bowel habits). However, it had no significant effects on dietary intakes, anthropometric indices, quality of life, and physical activity levels. The current trial is the first study evaluating the effects of propolis administration in patients with IBS.

Our results showed that propolis had no significant effect on energy intakes and energy-adjusted dietary intakes. In line with our results, Soleimani et al. reported that the administration of $900 \mathrm{mg} /$ day of propolis for 4 months in patients with non-alcoholic fatty liver disease (NAFLD) had no significant effect on energy and dietary intakes (16). In the study of Samadi et al., the administration of $900 \mathrm{mg} /$ day propolis for 3 months did not affect the dietary intakes in the propolis group in type 2 diabetic patients (26). In another study, consumption of $900 \mathrm{mg} /$ day propolis for 18 months did not affect energy and nutrients intakes in patients with type 2 diabetes mellitus (T2DM).(27) Furthermore, another study showed the consumption of a high dose of propolis (1500 mg/day) through 8 weeks did not affect energy and nutrients intakes in patients with T2DM (28).

Our results also showed that propolis had no significant effect on weight, BMI, and WC after adjusting the potential confounders such as changes in energy intakes and physical activity levels. In line with our results, the study of Soleimani et al. showed no significant effect of propolis administration on weight, BMI, body fat mass, and fat free mass in patients with NAFLD (16). Likewise, Mujica et al. reported that daily consumption of 30 drops of $3 \%$ propolis extract for 3 months did not affect weight, BMI, and WC (29). Another research showed that a daily supplement of $1500 \mathrm{mg}$ of propolis for 8 months did not affect body weight and BMI (30). Conversely, Samadi et al. reported that propolis administration (900 mg/day for 3 months) in T2DM reduced weight and BMl, while it did not affect WC (26). This inconsistency can be effect of confounders such as changes in dietary intakes and physical activity levels throughout the study of Samadi et al (26).

Our results also showed that propolis had no significant effect on IBS quality of life in patients with IBS after adjusting the potential confounders. Contrary to our findings, Pessolato et al. reported receive $5 \%$ propolis ointment administered daily for mices with grade 2 burns on the burn sites for 21 days improved their QOL (31). Also, the study of Samet et al. showed that $500 \mathrm{mg} / \mathrm{day}$ of propolis for 6 months can improve the QOL of patients with recurrent aphthous stomatitis in the oral cavity (32).

Our results showed that propolis administration improved anxiety state in patients with IBS after adjusting the potential confounders. The anxiolytic effects observed in propolis might be related to its terpenoids compounds, which can reduce adrenocorticotropic hormone (ACTH) levels and subsequently reduce cortisol levels and increase the activity of the body's own antioxidant defense system, which ultimately strengthens the antioxidant system in Brain tissue is through the hypothalamic-pituitary-adrenal axis (33).

Our results showed that propolis administration improved the IBS (score and grade) in patients with IBS after adjusting the potential confounders. Recent systematic review of pre-clinical studies concluded that propolis intake might have beneficial effects on many aspects of clinical, macroscopic, and histological features of colitis (34). Nonetheless, limited studies examined the effects of propolis on the severity of inflammation-based diseases in humans. A human study showed propolis decreased the severity of pain related to oral mucositis (35). Propolis by its anti-inflammatory effects could reduce the inflammation related to IBS disease, and based on this study findings it can reduce the severity of abnormal pain and dissatisfaction with bowel habits. Non-specific propolis extract is involved in the immune response by activating macrophages, which does this by releasing hydrogen peroxide and inhibiting the production of nitric oxide (dose-dependent effect), which can be affected by its effect on Inhibition of inducible nitric oxide synthase (iNOS) gene expression and iNOS catalytic activity is justified $(36,37)$. Laboratory studies have shown the inhibitory effect of propolis on free radicals $(38,39)$. Some of the specific effects shown by the aqueous form of propolis include an inhibitory effect on platelet aggregation, an inhibitory effect on the synthesis of prostaglandins in vitro, and inhibition of 5-lipoxygenase (5LOX) (40-42). Studies have also shown that alcoholic propolis extract inhibits transcription of the iNOS gene through its effect on Nuclear factor kappa B (NF-KB) sites in the NF-KB promoter, which is dose-dependent (43). Also, alcoholic extract of propolis can interfere with inflammatory response mechanisms, which has a very important effect on controlling cellular epithelial function (44). 
Propolis could also reduce the inflammatory cytokines (45). Propolis compounds such as caffeine phenyl ester inhibit NF-kB activity (Figure 3) (46).

The current trial had some strength. One of the most important strengths of this study was that it conducted on the IBS patients diagnosed by Rome IV criteria which is the newest tool for IBS diagnosis; also using stratified block randomization with a block size of 4 (based on IBS subtypes and sex) led to the distribution of features between the study groups and the other strengths of this study were the high compliance rate of patients to the treatment in each group. However, this trial had a few limitations including self-reporting of physical activity and dietary intakes.

\section{Conclusions}

The present trail, for the first time, revealed that supplementation with $900 \mathrm{mg} /$ day propolis for 6 weeks could significantly improve abdominal pain, decrease dissatisfaction with bowel habits as well as the reduction in the anxiety state. Although, propolis supplementation had no effect on IBS-QOL, dietary intakes, and anthropometric indices. This trial suggested that propolis could be used as adjunctive therapy in IBS disease to reduce abdominal pain and the anxiety of IBS patients. Further RCT studies on the effect of propolis supplementation on gut microbiome of IBS patients are suggested to achieve valid data in the management of IBS.

\section{Abbreviations}

ANCOVA: Analysis of covariance; BAl: Beck anxiety inventory; BMI: Body mass index; BSFS: Bristol stool form scale; GI: Gastrointestinal; HPLC: High-performance liquid chromatography; IPAQ-SF: International physical activity questionnaire-short form; IBS: Irritable bowel syndrome; IBS-C: Constipation subtype of IBS; IBS-M: Mixed subtype of IBS; IBS-QOL: Irritable bowel syndrome quality of life; IBS-SSS: Irritable bowel syndrome symptom severity scale; iNOS; Inducible nitric oxide synthase; MCC: Microcrystalline cellulose; METs: Metabolic equivalents; NF-kB: Nuclear factor kappa-light-chain-enhancer of activated B cells; OM: Oral mucositis; QOL: Quality of life; WC: Waist circumference.

\section{Declarations}

\section{Authorship}

$\mathrm{MM}, \mathrm{AO}, \mathrm{PA}, \mathrm{DS}$, and MA designed research and contributed to the conception of the project, development of the overall research plan, and study oversight. MM drafted the manuscript and analyzed and interpreted the data. MM and DS were the statistic counselors and PA diagnosed the patients with Rome IV criteria. MM was involved in the sampling and data collection. All authors have given final approval of the version to be published.

\section{Declaration of competing for interest}

All authors declare that there is no conflict of interest.

\section{Acknowledgment}

We sincerely thank the patients who participated in the present study.

\section{Funding}

The study was financially supported by the Nutrition Research Center of Tabriz University of Medical Sciences. The funder is not involved in the study design, collection, management, analysis, and interpretation, writing of the manuscript and the decision to submit the report for publication, including whether they will have ultimate authority over any of these activities. This is based on the data obtained from an MSc dissertation of first author (grant number: 63292) submitted to Tabriz University of Medical Sciences.

\section{Ethics and Approval for human experiments:}

This project was found to be in accordance with the ethical principles and the national norms and standards for conducting Medical Research in Iran. Evaluated by Tabriz University of Medical Sciences. Approval ID: IR.TBZMED.REC.1398.473. In the study, we used the Rome IV questionnaires for IBS disease (the Rome IV diagnostic questionnaire for IBS disease, Persian versions of IBS-SSS, and 
IBS-QOL questionnaires) after obtaining correspondence and authorization from Rome Foundation. The questionnaires were provided to the researchers under a contract.

The present trial was approved by the Ethics Committee of Tabriz University of Medical Sciences with ethics code:

IR.TBZMED.REC.1398.473 and was registered in the Iranian registry of clinical trials (https://en.irct.ir/trial/40983, registration date: 26/12/2019, registration number: IRCT20190708044154N1).

\section{References}

1. Rodiño-Janeiro BK, Vicario M, Alonso-Cotoner C, Pascua-García R, Santos J. A review of microbiota and irritable bowel syndrome: future in therapies. Advances in therapy. 2018;35(3):289-310.

2. Bai T, Xia J, Jiang Y, Cao H, Zhao Y, Zhang L, et al. Comparison of the Rome IV and Rome III criteria for IBS diagnosis: A crosssectional survey. Journal of gastroenterology and hepatology. 2017;32(5):1018-25.

3. Collins S, Piche T, Rampal P. The putative role of inflammation in the irritable bowel syndrome. Gut. 2001;49(6):743-5.

4. Ishihara S, Kawashima K, Fukuba N, Tada Y, Kotani S, Mishima Y, et al. Irritable bowel syndrome-like symptoms in ulcerative colitis patients in clinical remission: association with residual colonic inflammation. Digestion. 2019;99(1):46-51.

5. Saha L. Irritable bowel syndrome: pathogenesis, diagnosis, treatment, and evidence-based medicine. World Journal of Gastroenterology: WJG. 2014;20(22):6759.

6. Xu D, Chen VL, Steiner CA, Berinstein JA, Eswaran S, Waljee AK, et al. Efficacy of fecal microbiota transplantation in irritable bowel syndrome: a systematic review and meta-analysis. American Journal of Gastroenterology. 2019;114(7):1043-50.

7. Zhu Y, Zheng X, Cong Y, Chu H, Fried M, Dai N, et al. Bloating and distention in irritable bowel syndrome: the role of gas production and visceral sensation after lactose ingestion in a population with lactase deficiency. American Journal of Gastroenterology. 2013;108(9):1516-25.

8. Moayyedi P, Ford AC, Talley NJ, Cremonini F, Foxx-Orenstein AE, Brandt LJ, et al. The efficacy of probiotics in the treatment of irritable bowel syndrome: a systematic review. Gut. 2010;59(3):325-32.

9. Suzuki T, Hara $\mathrm{H}$. Role of flavonoids in intestinal tight junction regulation. The Journal of nutritional biochemistry. 2011;22(5):401-8.

10. Nina N, Quispe C, Jiménez-Aspee F, Theoduloz C, Feresín GE, Lima B, et al. Antibacterial activity, antioxidant effect and chemical composition of propolis from the Región del Maule, Central Chile. Molecules. 2015;20(10):18144-67.

11. Cornara L, Biagi M, Xiao J, Burlando B. Therapeutic properties of bioactive compounds from different honeybee products. Frontiers in pharmacology. 2017;8:412.

12. Xue M, Liu Y, Xu H, Zhou Z, Ma Y, Sun T, et al. Propolis modulates the gut microbiota and improves the intestinal mucosal barrier function in diabetic rats. Biomedicine \& Pharmacotherapy. 2019;118:109393.

13. Wang K, Jin X, Chen Y, Song Z, Jiang X, Hu F, et al. Polyphenol-rich propolis extracts strengthen intestinal barrier function by activating AMPK and ERK signaling. Nutrients. 2016;8(5):272.

14. Jalali M, Ranjbar T, Mosallanezhad Z, Mahmoodi M, Moosavian SP, Ferns G, et al. Effect of Propolis supplementation on serum CRP and TNF-a levels in adults: A systematic review and meta-analysis of clinical trials. Complementary Therapies in Medicine. 2020:102380.

15. Soleimani D, Miryan M, Tutunchi H, Navashenaq JG, Sadeghi E, Ghayour-Mobarhan M, et al. A systematic review of preclinical studies on the efficacy of propolis for the treatment of inflammatory bowel disease. Phytotherapy Research.

16. Soleimani D, Rezaie M, Rajabzadeh F, Gholizadeh Navashenaq J, Abbaspour M, Miryan M, et al. Protective effects of propolis on hepatic steatosis and fibrosis among patients with nonalcoholic fatty liver disease (NAFLD) evaluated by real-time twodimensional shear wave elastography: A randomized clinical trial. Phytotherapy Research. 2020.

17. Miryan M, Alavinejad P, Abbaspour M, Soleimani D, Ostadrahimi A. Does propolis affect the quality of life and complications in subjects with irritable bowel syndrome (diagnosed with Rome IV criteria)? A study protocol of the randomized, double-blinded, placebo-controlled clinical trial. Trials. 2020;21(1):1-10.

18. Han K, Wang J, Seo J-G, Kim H. Efficacy of double-coated probiotics for irritable bowel syndrome: a randomized double-blind controlled trial. Journal of gastroenterology. 2017;52(4):432-43. 
19. Baştürk A, Artan R, Yılmaz A. Efficacy of synbiotic, probiotic, and prebiotic treatments for irritable bowel syndrome in children: a randomized controlled trial. Turk J Gastroenterol. 2016;27(5):439-43.

20. Francis CY, Morris J, Whorwell PJ. The irritable bowel severity scoring system: a simple method of monitoring irritable bowel syndrome and its progress. Alimentary pharmacology \& therapeutics. 1997;11(2):395-402.

21. Drossman DA, Patrick DL, Whitehead WE, Toner BB, Diamant NE, Hu Y, et al. Further validation of the IBS-QOL: a disease-specific quality-of-life questionnaire. The American journal of gastroenterology. 2000;95(4):999-1007.

22. Fydrich T, Dowdall D, Chambless DL. Reliability and validity of the Beck Anxiety Inventory. Journal of anxiety disorders. 1992;6(1):55-61.

23. Beck AT, Steer R. Beck anxiety inventory (BAI). Überblick über Reliabilitäts-und Validitätsbefunde von klinischen und außerklinischen Selbst-und Fremdbeurteilungsverfahren. 1988:7.

24. Craig CL, Marshall AL, Sjöström M, Bauman AE, Booth ML, Ainsworth BE, et al. International physical activity questionnaire: 12country reliability and validity. Medicine \& science in sports \& exercise. 2003;35(8):1381-95.

25. A'hern R. Sample size tables for exact single-stage phase II designs. Statistics in medicine. 2001;20(6):859-66.

26. Samadi N, Mozaffari-Khosravi H, Rahmanian M, Askarishahi M. Effects of bee propolis supplementation on glycemic control, lipid profile and insulin resistance indices in patients with type 2 diabetes: a randomized, double-blind clinical trial. Journal of Integrative Medicine. 2017;15(2):124-34.

27. Zhao L, Pu L, Wei J, Li J, Wu J, Xin Z, et al. Brazilian green propolis improves antioxidant function in patients with type 2 diabetes mellitus. International journal of environmental research and public health. 2016;13(5):498.

28. Afsharpour F, Javadi M, Hashemipour S, Koushan Y. Propolis supplementation improves glycemic and antioxidant status in patients with type 2 diabetes: A randomized, double-blind, placebo-controlled study. Complementary Therapies in Medicine. 2019;43:283-8.

29. Mujica V, Orrego R, Pérez J, Romero P, Ovalle P, Zúñiga-Hernández J, et al. The role of propolis in oxidative stress and lipid metabolism: a randomized controlled trial. Evidence-Based Complementary and Alternative Medicine. 2017;2017.

30. Hesami S, Hashemipour S, Shiri-Shahsavar MR, Koushan Y, Haghighian HK. Administration of Iranian Propolis attenuates oxidative stress and blood glucose in type II diabetic patients: a randomized, double-blind, placebo-controlled, clinical trial. Caspian journal of internal medicine. 2019;10(1):48.

31. Pessolato AGT, dos Santos Martins D, Ambrósio CE, Mançanares CAF, de Carvalho AF. Propolis and amnion reepithelialise second-degree burns in rats. Burns. 2011;37(7):1192-201.

32. Samet N, Laurent C, Susarla SM, Samet-Rubinsteen N. The effect of bee propolis on recurrent aphthous stomatitis: a pilot study. Clinical oral investigations. 2007;11(2):143-7.

33. Li Y, Xuan H, Shou Q, Zhan Z, Lu X, Hu F-L. Therapeutic effects of propolis essential oil on anxiety of restraint-stressed mice. Human \& experimental toxicology. 2012;31(2):157-65.

34. Soleimani D, Miryan M, Tutunchi H, Navashenaq JG, Sadeghi E, Ghayour-Mobarhan M, et al. A systematic review of preclinical studies on the efficacy of propolis for the treatment of inflammatory bowel disease. Phytotherapy Research. 2020.

35. Al Jaouni SK, Al Muhayawi MS, Hussein A, Elfiki I, Al-Raddadi R, Al Muhayawi SM, et al. Effects of honey on oral mucositis among pediatric cancer patients undergoing chemo/radiotherapy treatment at King Abdulaziz University Hospital in Jeddah, Kingdom of Saudi Arabia. Evidence-Based Complementary and Alternative Medicine. 2017;2017.

36. Orsi R, Funari S, Soares A, Calvi S, Oliveira S, Sforcin J, et al. Immunomodulatory action of propolis on macrophage activation. Journal of Venomous Animals and Toxins. 2000;6(2):205-19.

37. Tan-no K, Nakajima T, Shoji T, Nakagawasai O, Niijima F, Ishikawa M, et al. Anti-inflammatory effect of propolis through inhibition of nitric oxide production on carrageenin-induced mouse paw edema. Biological and Pharmaceutical Bulletin. 2006;29(1):96-9.

38. Banskota AH, Tezuka Y, Adnyana IK, Midorikawa K, Matsushige K, Message D, et al. Cytotoxic, hepatoprotective and free radical scavenging effects of propolis from Brazil, Peru, the Netherlands and China. Journal of ethnopharmacology. 2000;72(1-2):23946.

39. Alencar S, Oldoni T, Castro M, Cabral I, Costa-Neto C, Cury J, et al. Chemical composition and biological activity of a new type of Brazilian propolis: red propolis. Journal of ethnopharmacology. 2007;113(2):278-83.

Page 9/18 
40. Dobrowolski JW, Vohora S, Sharma K, Shah SA, Naqvi S, Dandiya P. Antibacterial, antifungal, antiamoebic, antiinflammatory and antipyretic studies on propolis bee products. Journal of ethnopharmacology. 1991;35(1):77-82.

41. Massaro FC, Brooks PR, Wallace HM, Russell FD. Cerumen of Australian stingless bees (Tetragonula carbonaria): gas chromatography-mass spectrometry fingerprints and potential anti-inflammatory properties. Naturwissenschaften. 2011;98(4):329-37.

42. Khayyal M, El-Ghazaly M, El-Khatib A. Mechanisms involved in the antiinflammatory effect of propolis extract. Drugs under experimental and clinical research. 1993;19(5):197-203.

43. Song YS, Park E-H, Hur GM, Ryu YS, Kim YM, Jin C. Ethanol extract of propolis inhibits nitric oxide synthase gene expression and enzyme activity. Journal of Ethnopharmacology. 2002;80(2-3):155-61.

44. Xuan H, Zhu R, Li Y, Hu F. Inhibitory effect of chinese propolis on phosphatidylcholine-specific phospholipase $\mathrm{C}$ activity in vascular endothelial cells. Evidence-Based Complementary and Alternative Medicine. 2010;2011.

45. Mehrnoosh Z, Maryam J, Narjes Z, Hemmati AA, Niloofar N. The Effect of Iranian Propolis on Glucose Metabolism, Lipid Profile, Insulin Resistance, Renal Function and Inflammatory Biomarkers in Patients with Type 2 Diabetes Mellitus: A Randomized Double-Blind Clinical Trial. Scientific Reports (Nature Publisher Group). 2019;9(1).

46. Hämäläinen M, Nieminen R, Vuorela P, Heinonen M, Moilanen E. Anti-inflammatory effects of flavonoids: genistein, kaempferol, quercetin, and daidzein inhibit STAT-1 and NF-KB activations, whereas flavone, isorhamnetin, naringenin, and pelargonidin inhibit only NF-KB activation along with their inhibitory effect on iNOS expression and NO production in activated macrophages. Mediators of inflammation. 2007;2007.

\section{Tables}




\begin{tabular}{|c|c|c|c|c|}
\hline \multicolumn{2}{|l|}{ Variables } & & $\begin{array}{l}\text { Placebo group } \\
(N=25)\end{array}$ & P-value \\
\hline \multicolumn{2}{|c|}{ Age; years } & $38.92 \pm 12.65$ & $44.92 \pm 12.10$ & $0.090^{+}$ \\
\hline \multicolumn{2}{|c|}{ Females; n (\%) } & $13(50 \%)$ & $14(56 \%)$ & $0.781^{\ddagger}$ \\
\hline \multicolumn{2}{|c|}{ Married; n (\%) } & 19 (73.07\%) & $23(92 \%)$ & $0.076^{\ddagger}$ \\
\hline \multicolumn{2}{|c|}{ Academic Education; n (\%) } & $10(38.46 \%)$ & $11(44 \%)$ & $0.885^{\ddagger}$ \\
\hline \multicolumn{2}{|c|}{ Employee; n (\%) } & $20(77 \%)$ & $20(80 \%)$ & $0.761^{\ddagger}$ \\
\hline \multicolumn{2}{|c|}{ METs; minutes/week } & 691.50 [196.00 - 1629.00] & 360.00 [173.25 - 1768.00] & $0.883^{+}$ \\
\hline \multicolumn{2}{|c|}{ IBS Duration; years } & $12.32 \pm 10.5$ & $8.31 \pm 7.36$ & $0.366^{\dagger}$ \\
\hline \multirow[t]{2}{*}{ IBS Type } & IBS-C; n (\%) & $19(73.07 \%)$ & $(68 \%) 17$ & \multirow[t]{2}{*}{$0.764^{\ddagger}$} \\
\hline & IBS-M; n (\%) & $7(26.92 \%)$ & $(32 \%) 8$ & \\
\hline \multirow[t]{4}{*}{ Anxiety } & Normal; n (\%) & $6(23.1 \%)$ & $6(24 \%)$ & \multirow[t]{4}{*}{$0.952^{\ddagger}$} \\
\hline & Mild; n (\%) & $8(30.8 \%)$ & $6(24 \%)$ & \\
\hline & Moderate; n (\%) & $6(23.1 \%)$ & $6(24 \%)$ & \\
\hline & Severe; n (\%) & $6(23.1 \%)$ & $7(28 \%)$ & \\
\hline \multicolumn{5}{|c|}{$\begin{array}{l}\text { Abbreviations. IBS, Irritable bowel syndrome; IBS-C, Constipation subtype of IBS; IBS-M, Mixed subtype of IBS; METs, Metabolic } \\
\text { equivalents }\end{array}$} \\
\hline \multicolumn{5}{|c|}{$\begin{array}{l}\text { Physical activity level are presented as median [25th, 75th]. Age and duration of IBS are presented as mean } \pm \text { SD; other variables } \\
\text { are presented as number }(\%) \text {. }\end{array}$} \\
\hline \multicolumn{5}{|c|}{$\begin{array}{l}\text { † Values were obtained from independent samples t-test. } \\
\ddagger \text { Values were obtained from Chi-square test. }\end{array}$} \\
\hline
\end{tabular}


Table 2. Energy-adjusted nutrients intake across study follow-up

\begin{tabular}{|c|c|c|c|c|c|c|c|c|c|c|c|}
\hline \multirow[t]{2}{*}{ Variables } & \multicolumn{4}{|c|}{ Propolis group } & \multicolumn{3}{|c|}{ Control group } & \multicolumn{4}{|c|}{ Effect } \\
\hline & week $_{0}$ & week $_{3}$ & week $_{6}$ & $\mathrm{P}^{\mathrm{a}}$ & week $_{0}$ & week $_{3}$ & week $_{6}$ & $P^{a}$ & $\mathrm{P}^{\mathrm{b}}$ & $\mathrm{P}^{\mathrm{C}}$ & $P^{d}$ \\
\hline Energy (Kcal) & $\begin{array}{l}1200 \\
(389.01)\end{array}$ & $\begin{array}{l}1263 \\
(391.47)\end{array}$ & $\begin{array}{l}1287 \\
(454.7)\end{array}$ & 0.665 & $\begin{array}{l}1373 \\
(475.28)\end{array}$ & $\begin{array}{l}1251 \\
(533.31)\end{array}$ & $\begin{array}{l}1175 \\
(530.36)\end{array}$ & 0.366 & 0.851 & 0.81 & 0.240 \\
\hline Protein (g) & $\begin{array}{l}52.54 \\
(18.44)\end{array}$ & $\begin{array}{l}54.72 \\
(17.41)\end{array}$ & $\begin{array}{l}55.19 \\
(17.19)\end{array}$ & 0.298 & $\begin{array}{l}60.17 \\
(21.38)\end{array}$ & $\begin{array}{l}54 \\
(23.47)\end{array}$ & $\begin{array}{l}51.06 \\
(20.39)\end{array}$ & 0.801 & 0.801 & 0.667 & 0.251 \\
\hline Fat (g) & $\begin{array}{l}22.25 \\
(9.97)\end{array}$ & $\begin{array}{l}25.34 \\
(5.59)\end{array}$ & $\begin{array}{l}26.14 \\
(7.04)\end{array}$ & 0.233 & $\begin{array}{l}26.60 \\
(10.75)\end{array}$ & $\begin{array}{l}25.11 \\
(7.54)\end{array}$ & $\begin{array}{l}24.19 \\
(7.34)\end{array}$ & 0.580 & 0.742 & 0.945 & 0.164 \\
\hline $\begin{array}{l}\text { Carbohydrate } \\
\text { (g) }\end{array}$ & $\begin{array}{l}119.95 \\
(61.65)\end{array}$ & $\begin{array}{l}210.04 \\
(63.55)\end{array}$ & $\begin{array}{l}210.97 \\
(81.53)\end{array}$ & 0.744 & $\begin{array}{l}228.49 \\
(77.99)\end{array}$ & $\begin{array}{l}207.99 \\
(87.78)\end{array}$ & $\begin{array}{l}191.24 \\
(96.77)\end{array}$ & 0.305 & 0.871 & 0.405 & 0.238 \\
\hline $\begin{array}{l}\text { Soluble Fiber } \\
\text { (g) }\end{array}$ & $\begin{array}{l}270 \\
(130)\end{array}$ & 290 (10) & $\begin{array}{l}320 \\
(110)\end{array}$ & 0.166 & $\begin{array}{l}430 \\
(170)\end{array}$ & $290(30)$ & $\begin{array}{l}290 \\
(110)\end{array}$ & 0.178 & 0.624 & 0.423 & 0.134 \\
\hline $\begin{array}{l}\text { Insoluble } \\
\text { fiber }(\mathrm{g})\end{array}$ & $\begin{array}{l}1560 \\
(1440)\end{array}$ & $\begin{array}{l}1590 \\
(50)\end{array}$ & $\begin{array}{l}1770 \\
(690)\end{array}$ & 0.65 & $\begin{array}{l}2430 \\
(2050)\end{array}$ & $\begin{array}{l}1590 \\
(90)\end{array}$ & $\begin{array}{l}1550 \\
(705)\end{array}$ & 0.052 & 0.258 & 0.149 & 0.051 \\
\hline $\begin{array}{l}\text { Fructose } \\
\text { (mg) }\end{array}$ & $\begin{array}{l}6090 \\
(1950)\end{array}$ & $\begin{array}{l}6860 \\
(590)\end{array}$ & $\begin{array}{l}7520 \\
(1610)\end{array}$ & 0.223 & $\begin{array}{l}6870 \\
(2250)\end{array}$ & $\begin{array}{l}6950 \\
(1045)\end{array}$ & $\begin{array}{l}7125 \\
(1920)\end{array}$ & 0.863 & 0.625 & 0.980 & 0.101 \\
\hline Lactose (mg) & $\begin{array}{l}3250 \\
(840)\end{array}$ & $\begin{array}{l}2970 \\
(520)\end{array}$ & $\begin{array}{l}3920 \\
(1680)\end{array}$ & 0.004 & $\begin{array}{l}3680 \\
(1030)\end{array}$ & $\begin{array}{l}2760 \\
(590)\end{array}$ & $\begin{array}{l}3510 \\
(1810)\end{array}$ & 0.023 & 0.974 & 0.001 & 0.172 \\
\hline $\begin{array}{l}\text { Caffeine } \\
\text { (mg) }\end{array}$ & $\begin{array}{l}570 \\
(340)\end{array}$ & $\begin{array}{l}1090 \\
(850)\end{array}$ & $180(1)$ & 0.001 & $\begin{array}{l}870 \\
(520)\end{array}$ & $\begin{array}{l}1020 \\
(1090)\end{array}$ & $180(30)$ & 0.003 & 0.66 & 0.001 & 0.46 \\
\hline
\end{tabular}

Values are expressed as mean (SD).

a Paired sample $t$-test.

${ }^{\mathrm{b}}$ P-intervention for comparing within each group trend, Repeated-measure analysis of variance test.

${ }^{\mathrm{c}} \mathrm{P}$-time, Repeated-measure analysis of variance test.

d P-interaction, Repeated-measure analysis of variance test.

Table 3. Adjusted mean changes in anthropometric parameters in the both groups.

\begin{tabular}{|c|c|c|c|c|c|c|}
\hline Variables & Group & Before & After & P-valuet & Changesł & P-value $\neq$ \\
\hline \multirow[t]{2}{*}{ Weight; kg } & Propolis & $72.10 \pm 13.65$ & $72.28 \pm 13.84$ & 0.717 & $0.114 \pm 0.094$ & \multirow[t]{2}{*}{0.677} \\
\hline & Placebo & $75.64 \pm 15.08$ & $75.61 \pm 15.08$ & 0.939 & $0.063 \pm 0.102$ & \\
\hline \multirow[t]{2}{*}{$\mathrm{BMl} ; \mathrm{kg} / \mathrm{m}^{2}$} & Propolis & $25.61 \pm 4.00$ & $25.58 \pm 3.96$ & 0.711 & $-0.088 \pm 0.028$ & \multirow[t]{2}{*}{0.775} \\
\hline & Placebo & $27.75 \pm 5.85$ & $27.73 \pm 5.81$ & 0.877 & $0.023 \pm 0.031$ & \\
\hline \multirow[t]{2}{*}{ WC; $\mathrm{cm}$} & Propolis & $85.94 \pm 15.77$ & $87.28 \pm 2.45$ & 0.711 & $1.34 \pm 0.245$ & \multirow[t]{2}{*}{0.593} \\
\hline & Placebo & $95.20 \pm 4.00$ & $94.96 \pm 2.74$ & 0.784 & $-0.23 \pm 0.268$ & \\
\hline
\end{tabular}

Abbreviations. WC: Waist circumference; BMI: Body mass index

Data are presented as mean \pm standard deviation.

† Values were obtained from Paired- sample t-test.

¥ Values were obtained from ANCOVA test with baseline values and changes in physical activity and energy intake as covariates. 
Table 4. Quality of life of IBS participants throughout the study.

\begin{tabular}{|c|c|c|c|c|}
\hline Variables & & Propolis $(n=26)$ & Placebo $(n=25)$ & Mean Difference (95\% Cl), P \\
\hline \multirow[t]{3}{*}{ Dysphoria } & Baseline & $59.12(31.03)$ & $59.61(28.37)$ & $-0.049(-16.23,17.21), 0.953^{b}$ \\
\hline & 6weeks & $72.75(22.52)$ & $64.54(25.04)$ & $\begin{array}{l}8.21(-21.62,5.21), 0.225^{b}, 0.813^{c} \\
0.404^{d}\end{array}$ \\
\hline & $\begin{array}{l}\mathrm{MD}(95 \% \\
\mathrm{Cl}), \mathrm{P}^{\mathrm{a}}\end{array}$ & $\begin{array}{l}13.6(-22.11,-5.13) \\
0.003\end{array}$ & $\begin{array}{l}1.69(-14.66,4.80) \\
0.307\end{array}$ & \\
\hline \multirow{3}{*}{$\begin{array}{l}\text { Interference with } \\
\text { activity }\end{array}$} & Baseline & $55.85(25.20)$ & $59.34(21.40)$ & $-3.49(-9.65,16,62), 0.597^{b}$ \\
\hline & 6weeks & $67.42(24.55)$ & $54.31(18.95)$ & $\begin{array}{l}13.11(-25.43,-0.79), 0.037^{b}, 0.424^{c} \\
0.932^{d}\end{array}$ \\
\hline & $\begin{array}{l}\mathrm{MD}(95 \% \\
\mathrm{Cl}), \mathrm{P}^{\mathrm{a}}\end{array}$ & $\begin{array}{l}11.57(-19.9,-4.05) \\
\mathbf{0 . 0 0 4}\end{array}$ & $\begin{array}{l}-5.02(-0.42,10.48) \\
0.069\end{array}$ & \\
\hline \multirow[t]{3}{*}{ Body image } & Baseline & $70.75(28.28)$ & $73.63(13.10)$ & $-2.88(-9.44,15.21), 0.640^{b}$ \\
\hline & 6weeks & $80.89(19.49)$ & $69.71(13.62)$ & $\begin{array}{l}11.18(-20,60,-1.74), 0.021^{b}, 0.039^{c} \\
0.193^{d}\end{array}$ \\
\hline & $\begin{array}{l}\mathrm{MD}(95 \% \\
\mathrm{Cl}), \mathrm{P}^{\mathrm{a}}\end{array}$ & $\begin{array}{l}10.14(-15.81,-4.46) \\
0.001\end{array}$ & $\begin{array}{l}3.91(-1.24,9.07) \\
0.130-\end{array}$ & \\
\hline \multirow[t]{3}{*}{ Health worry } & Baseline & $45.66(29.96)$ & $47.75(25.77)$ & $-2.09(-13.61,17.79), 0.790^{b}$ \\
\hline & 6weeks & $63.33(27.42)$ & $48.39(23.69)$ & $\begin{array}{l}14.94(-30.73,-3.14), 0.017^{b}, 0.243^{c} \\
0.824^{d}\end{array}$ \\
\hline & $\begin{array}{l}\mathrm{MD}(95 \% \\
\mathrm{Cl}), \mathrm{P}^{\mathrm{a}}\end{array}$ & $\begin{array}{l}17.66(-30.33,-9.26) \\
0.001\end{array}$ & $\begin{array}{l}0.64(-9.21,7.68) \\
0.853\end{array}$ & \\
\hline \multirow[t]{3}{*}{ Food avoidance } & Baseline & $53.33(30.80)$ & $53.83(21.38)$ & $-0.5(-14.89,15.91), 0.947^{b}$ \\
\hline & 6weeks & $64(22.29)$ & $57.37(24.41)$ & $\begin{array}{l}6.63(-21.18,7.93), 0.365^{b}, 0.876^{c} \\
0.645^{d}\end{array}$ \\
\hline & $\begin{array}{l}\mathrm{MD}(95 \% \\
\mathrm{Cl}), \mathrm{P}^{\mathrm{a}}\end{array}$ & $\begin{array}{l}10.66(-20.32,-1.01) \\
0.032\end{array}$ & $\begin{array}{l}3.52(-12.95,5.90) \\
0.449\end{array}$ & \\
\hline \multirow[t]{3}{*}{ Social reaction } & Baseline & $70.01(21.77)$ & $73.55(21.38)$ & $-3.54(-8.59,15.69), 0.560^{b}$ \\
\hline & 6weeks & $82.26(14.40)$ & $74.17(13.54)$ & $\begin{array}{l}8.09(-15.95,-0.22), 0.044^{b}, 0.415^{c} \\
0.423^{d}\end{array}$ \\
\hline & $\begin{array}{l}\mathrm{MD}(95 \% \\
\mathrm{Cl}) \mathrm{P}^{\mathrm{a}}\end{array}$ & $\begin{array}{l}12.25(-17.73,-6.76) \\
0.0001\end{array}$ & $\begin{array}{l}0.61(-7.23,6,00) \\
0.850\end{array}$ & \\
\hline \multirow[t]{3}{*}{ Sexual } & Baseline & $72.50(31.04)$ & $75(29.36)$ & $-2.5(-14.49,19,49), 0.769^{b}$ \\
\hline & 6 weeks & $77(22.44)$ & $69.23(31.07)$ & $\begin{array}{l}7.77(-23.07,7.53), 0.313^{b}, 0.679^{c} \\
0.705^{d}\end{array}$ \\
\hline & $\begin{array}{l}\text { MD }(95 \% \\
\text { Cl), } P^{a}\end{array}$ & $4.5(-14.13,5.13), 0.345$ & $\begin{array}{l}5.76(-6.11,17.65) \\
0.327-\end{array}$ & \\
\hline \multirow[t]{2}{*}{ Relationships } & Baseline & $56(29.41)$ & $58.65(22.54)$ & $-2.65(-12.05,17,36), 0.179^{b}$ \\
\hline & 6weeks & $66(23.80)$ & $60.89(21.57)$ & $\begin{array}{l}5.11(-17.87,7.67), 0.426^{b}, 0.803^{c} \\
0.217^{d}\end{array}$ \\
\hline
\end{tabular}




\begin{tabular}{|c|c|c|c|c|}
\hline & $\begin{array}{l}\mathrm{MD}(95 \% \\
\mathrm{Cl}) \mathrm{P}^{\mathrm{a}}\end{array}$ & $10(-17.75,-2.24), 0.014$ & $\begin{array}{l}2.24(-9.40,4.91) \\
0.524\end{array}$ & \\
\hline \multirow[t]{3}{*}{ Overall score } & Baseline & $59.90(24.77)$ & $62.10(18.31)$ & $-2.2(-10.02,14.42), 0.719^{b}$ \\
\hline & 6 weeks & $71.96(19.24)$ & $62.08(17.63)$ & $\begin{array}{l}9.88(-10.13,14.53), 0.062^{b}, 0.565^{c} \\
0.708^{d}\end{array}$ \\
\hline & $\begin{array}{l}\mathrm{MD}(95 \% \\
\mathrm{Cl}), \mathrm{P}^{\mathrm{a}}\end{array}$ & $\begin{array}{l}12.05(-18.35,-5.75) \\
0.001\end{array}$ & $\begin{array}{l}0.26(-5.87,5.83) \\
0.993\end{array}$ & \\
\hline
\end{tabular}

IBS, Irritable bowel syndrome.

Mean (SD) and Mean Difference $(95 \% \mathrm{Cl})$ are presented for data.

a Paired samples $t$-test.

${ }^{\mathrm{b}}$ Independent samples $t$-test.

${ }^{c}$ ANCOVA test, adjusted for baseline values (Model 1).

${ }^{d}$ ANCOVA test, adjusted for baseline values, changes in physical activity, and energy intake (Model 2). 
Table 5. IBS symptoms severity score of participants throughout of study.

\begin{tabular}{|c|c|c|c|c|}
\hline Variables & & Propolis $(n=26)$ & Placebo $(n=25)$ & Mean Difference $(95 \% \mathrm{Cl}), \mathrm{P}$ \\
\hline \multirow{3}{*}{$\begin{array}{l}\text { Severity of abdominal } \\
\text { pain }\end{array}$} & Baseline & $55.76 \pm 28.16$ & $55.60 \pm 35.55$ & $0.16(-17.23,17.57) ; 0.984^{b}$ \\
\hline & 6weeks & $33.07 \pm 26.94$ & $53.60 \pm 29.98$ & $\begin{array}{l}-20.53(-36.55,-4.49) ; 0.013^{b} \\
0.020^{c}, 0.040^{d}\end{array}$ \\
\hline & $\begin{array}{l}\mathrm{MD}(95 \% \\
\mathrm{Cl}) ; \mathrm{P}^{\mathrm{a}}\end{array}$ & $\begin{array}{l}-22.69(-36.18,-9.19) \\
0.002\end{array}$ & $\begin{array}{l}-2.00(-7.38,11.38) \\
0.664\end{array}$ & \\
\hline \multirow{3}{*}{$\begin{array}{l}\text { Frequency of abdominal } \\
\text { pain }\end{array}$} & Baseline & $5.15 \pm 3.35$ & $5.08 \pm 3.39$ & $0.07(-1.82,1.97) ; 0.938^{b}$ \\
\hline & 6weeks & $3.07 \pm 3.22$ & $4.80 \pm 2.76$ & $\begin{array}{l}-1.73(-3.41,-0.02) ; 0.046^{b}, 0.150^{c} \\
0.153^{d}\end{array}$ \\
\hline & $\begin{array}{l}\mathrm{MD}(95 \% \\
\mathrm{Cl}) ; \mathrm{P}^{\mathrm{a}}\end{array}$ & $\begin{array}{l}-2.70(-3.80,-0.34) \\
0.021\end{array}$ & $\begin{array}{l}-0.28(-1.23,0.67) \\
0.552\end{array}$ & \\
\hline \multirow{3}{*}{$\begin{array}{l}\text { Severity of abdominal } \\
\text { distention }\end{array}$} & Baseline & $64.61 \pm 32.02$ & $63.60 \pm 22.70$ & $1.01(-14.66,16.69) ; 0.897^{b}$ \\
\hline & 6weeks & $42.69 \pm 25.22$ & $48.80 \pm 19.64$ & $\begin{array}{l}-6.11(-18.86,6.65) ; 0.341^{b}, 0.327^{c} \\
0.305^{d}\end{array}$ \\
\hline & $\begin{array}{l}\mathrm{MD}(95 \% \\
\mathrm{Cl}), \mathrm{P}^{\mathrm{a}}\end{array}$ & $\begin{array}{l}-21.92(-32.82,-11.02) \\
0.001\end{array}$ & $\begin{array}{l}-14.80(-25.79,3.80) \\
0.010\end{array}$ & \\
\hline \multirow{3}{*}{$\begin{array}{l}\text { Dissatisfaction with } \\
\text { bowel habits }\end{array}$} & Baseline & $60.00 \pm 26.83$ & $64.40 \pm 26.93$ & $-4.40(-19.53,10.73), 0.562^{b}$ \\
\hline & 6weeks & $42.69 \pm 23.24$ & $64.00 \pm 24.15$ & $\begin{array}{l}-21.31(-34.64,-7.96), \mathbf{0 . 0 0 2 ^ { b }} \\
\mathbf{0 . 0 0 6}, \mathbf{0}^{\mathrm{O}} \mathbf{0 . 0 3 5 ^ { \mathrm { d } }}\end{array}$ \\
\hline & $\begin{array}{l}\mathrm{MD}(95 \% \\
\mathrm{Cl}), \mathrm{P}^{\mathrm{a}}\end{array}$ & $\begin{array}{l}-17.30(-27.56,-7.05) \\
0.002\end{array}$ & $\begin{array}{l}-0.40(-12.34,13.14) \\
0.949\end{array}$ & \\
\hline \multirow{3}{*}{$\begin{array}{l}\text { Interference with quality } \\
\text { of life }\end{array}$} & Baseline & $46.92 \pm 35.52$ & $55.60 \pm 29.45$ & $-8.68(-27.07,9.72), 0.348^{b}$ \\
\hline & 6weeks & $34.23 \pm 28.16$ & $53.60 \pm 24.81$ & $\begin{array}{l}-19.37(-34.32,-4.40), 0.012^{b} \\
\mathbf{0 . 0 2 3}^{c}, 0.207^{d}\end{array}$ \\
\hline & $\begin{array}{l}\text { MD }(95 \% \\
C l), P^{a}\end{array}$ & $\begin{array}{l}-12.69(-24,59,-0.78) \\
0.038\end{array}$ & $\begin{array}{l}-2.00(-18.25,14.25) \\
0.802\end{array}$ & \\
\hline \multirow[t]{3}{*}{ Overall score } & Baseline & $288.84 \pm 111.40$ & $290.00 \pm 108.97$ & $-1.16(-73.19,50.88), 0.719^{b}$ \\
\hline & 6weeks & $183.46 \pm 106.46$ & $268.00 \pm 81.54$ & $\begin{array}{l}-84.54(-138.06,-31.01), 0.003^{b} \\
0.008^{c}, 0.036^{d}\end{array}$ \\
\hline & $\begin{array}{l}\mathrm{MD}(95 \% \\
\mathrm{Cl}), \mathrm{P}^{\mathrm{a}}\end{array}$ & $\begin{array}{l}-95.38(-139.89 \\
-50.87), 0.0001\end{array}$ & $\begin{array}{l}-22.00(-60.74 \\
16.74), 0.253\end{array}$ & \\
\hline
\end{tabular}

Abbreviation. IBS, Irritable bowel syndrome

Mean (SD) and Mean Difference $(95 \% \mathrm{Cl})$ are presented for data.

a Paired samples $t$-test.

${ }^{\mathrm{b}}$ Independent samples $t$-test.

c ANCOVA test, adjusted for baseline values (Model 1).

${ }^{d}$ ANCOVA test, adjusted for baseline values, changes in physical activity and energy intake (Model 2). 
Figures

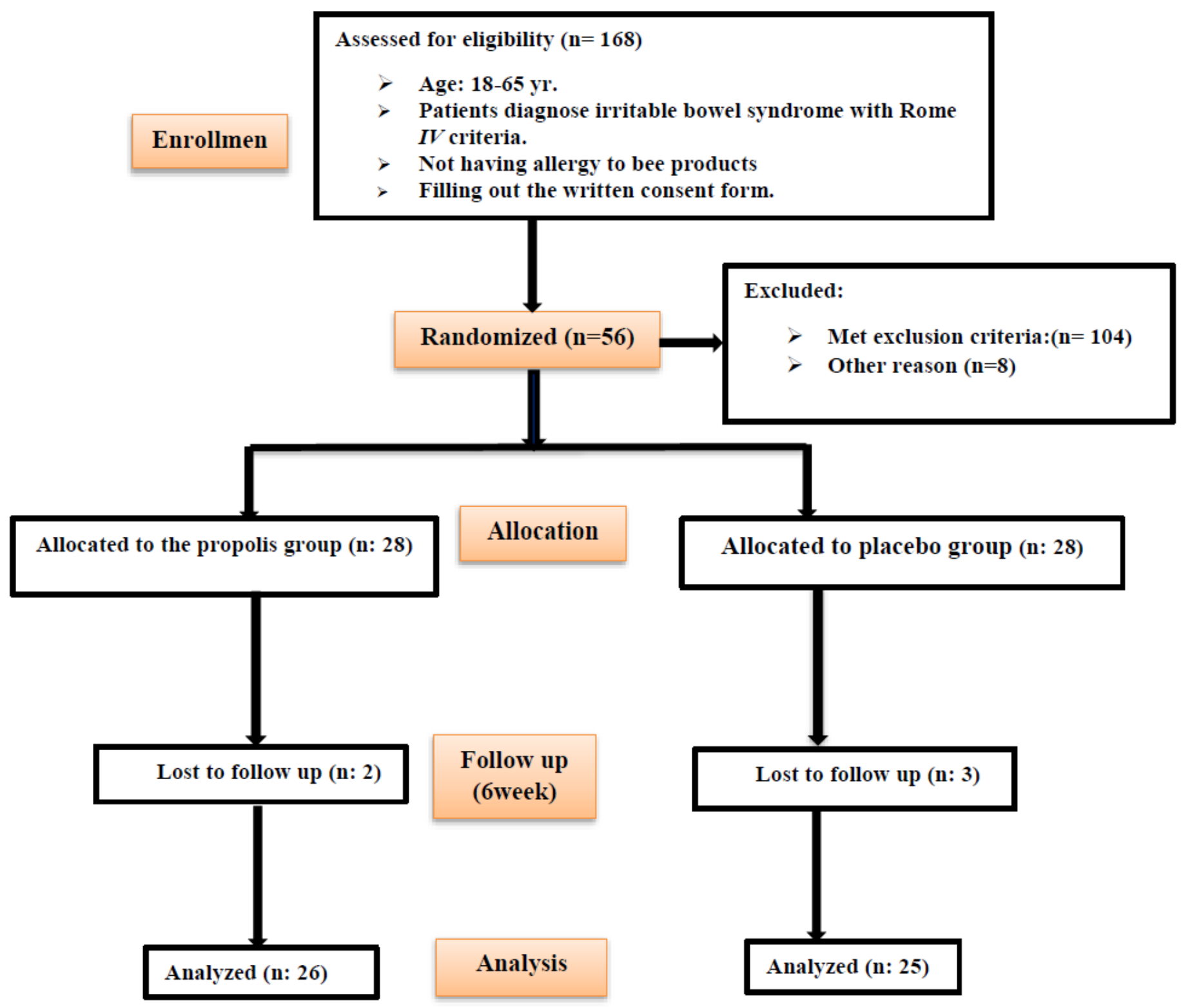

Figure 1

Study flow of enrolment, allocation, intervention, and assessment. 


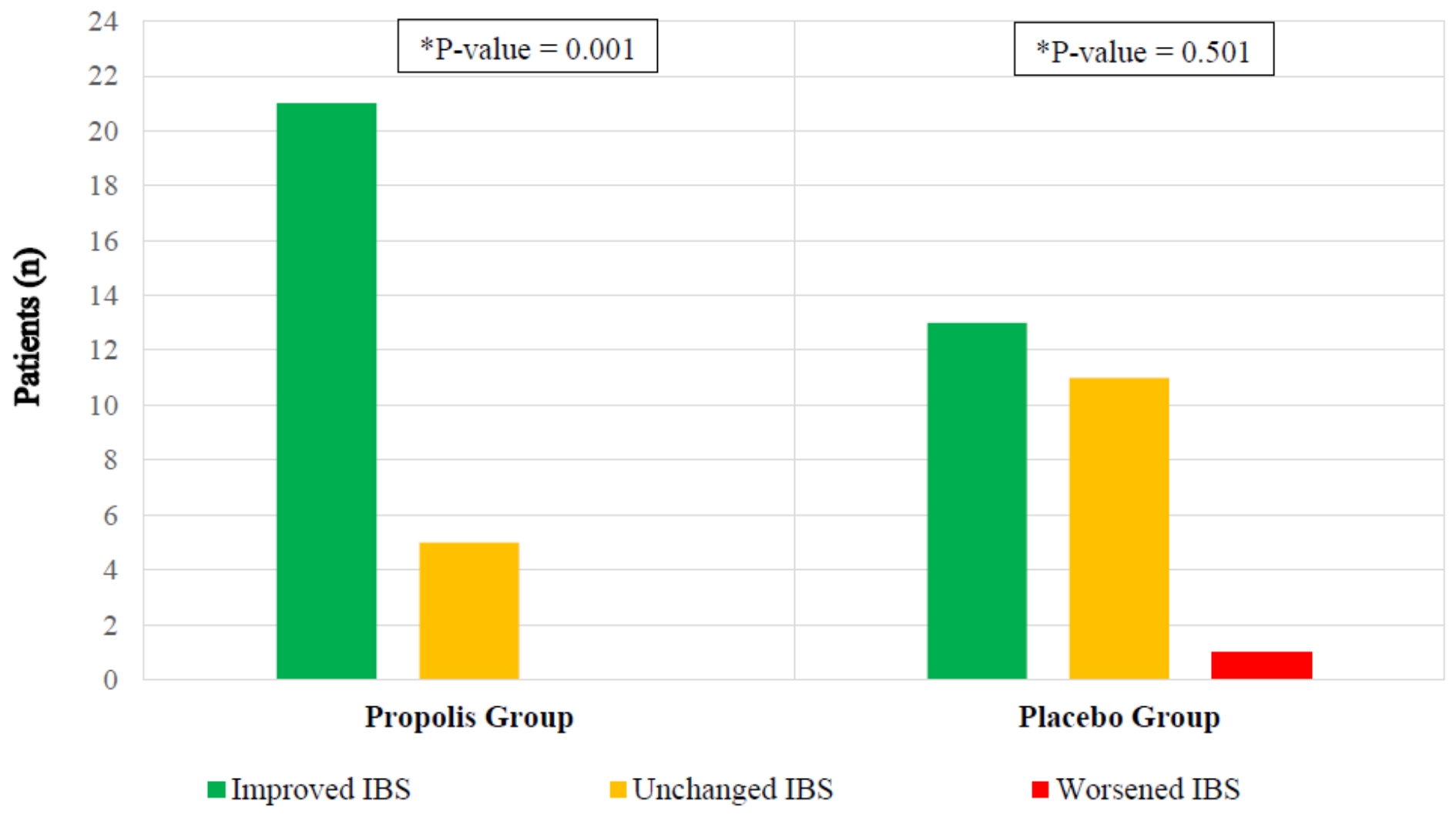

Figure 2

The changes in the severity of IBS from baseline to 6-week intervention in the propolis and placebo group. * Within-group comparisons with the use of a Wilcoxon rank-sum test showed a significant improvement in the degree of IBS in the propolis group from baseline to 6-week intervention. Mann-Whitney $U$ test showed that the improvement in the degree of IBS in the propolis group was significantly higher than the placebo group $(P$ value $=0.015)$. 


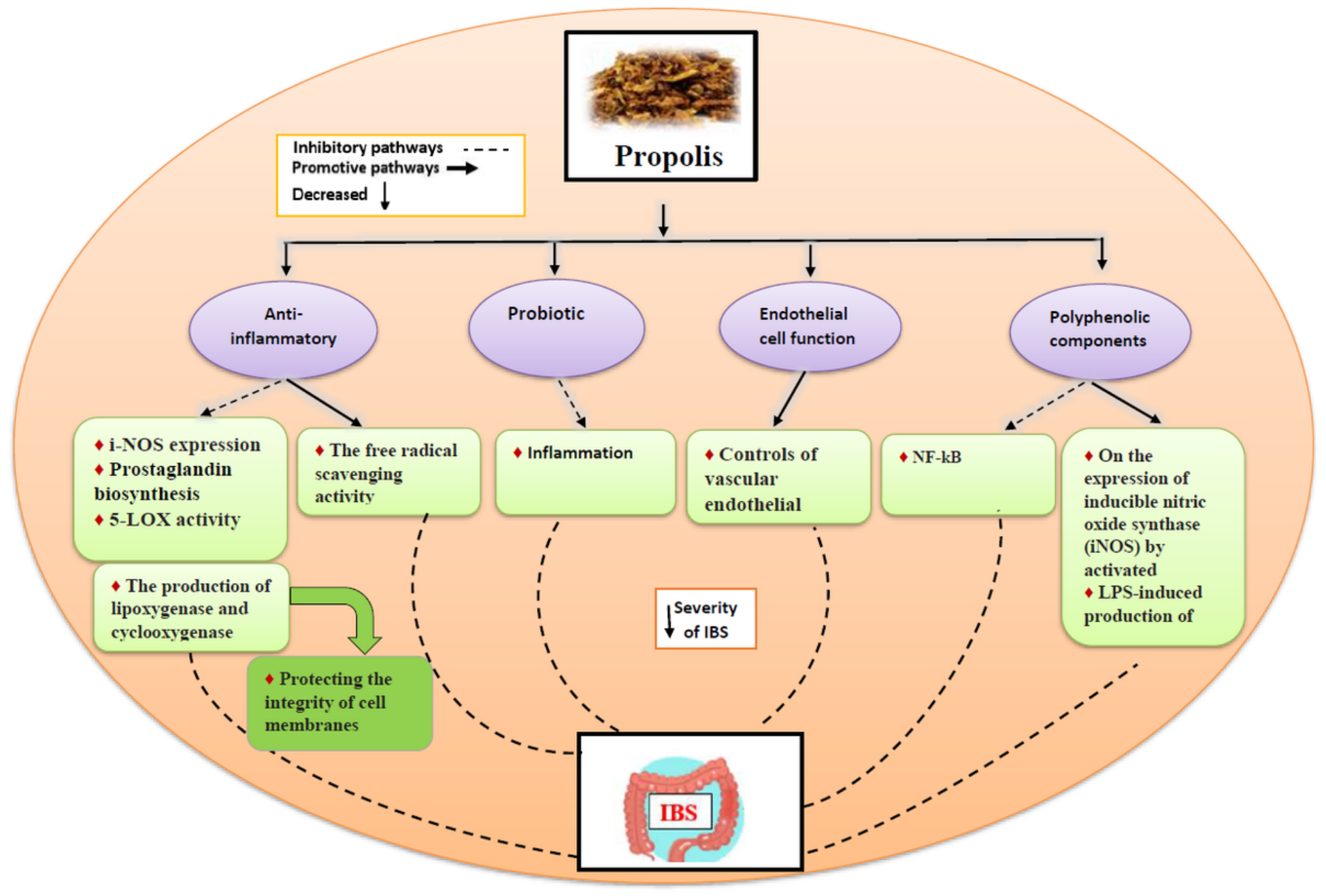

Figure 3

Possible mechanisms of the actions of propolis in the management of IBS. IBS; Irritable bowel syndrome, iNOS; Inducible nitric oxide synthase, 5-LOX; 5-lipoxygenase, NF-kB; nuclear factor kappa-light-chain-enhancer of activated B cells, LPS; Lipopolysaccharides. 